\title{
Lipid rafts are important for the association of RANK and TRAF6
}

\author{
Hyunil Ha ${ }^{1,3}$, Han Bok Kwak ${ }^{1,2,3}$, \\ Soo Woong Lee ${ }^{1,2,3}$, Hong-Hee $\mathrm{Kim}^{2,4}$, \\ and Zang Hee Lee $e^{1,2,3,5}$
}

\author{
${ }^{1}$ National Research Laboratory for Bone Metabolism \\ ${ }^{2}$ Research Center for Proteineous Materials \\ ${ }^{3}$ School of Dentistry \\ Chosun University, Gwangju 501-759, Korea \\ ${ }^{4}$ Department of Cell and Developmental Biology \\ College of Dentistry, Seoul National University \\ Seoul 110-749, Korea \\ ${ }^{5}$ Corresponding author: Tel, 82-62-230-6872; \\ Fax, 82-62-227-6589; E-mail, jhblee@mail.chosun.ac.kr
}

Accepted 19 June 2003

Abbreviations: MAPK, mitogen-activated protein kinase; MCD, methyl- $\beta$-cyclodextrin; RANK, receptor activator of NF- $\mathrm{kB}$; TLR, Toll-like receptor; TNFR, TNF receptor; TRAF, TNF receptorassociated factor

\begin{abstract}
Rafts, cholesterol- and sphingolipid-rich membrane microdomains, have been shown to play an im. portant role in immune cell activation. More recently rafts were implicated in the signal transduction by members of the TNF receptor (TNFR) family. In this study, we provide evidences that the raft microdomain has a crucial role in RANK (receptor activator of NF-KB) signaling. We found that the majority of the ectopically expressed RANK and substantial portion of endogenous TRAF2 and TRAF6 were detected in the low-density raft fractions. In addition, TRAF6 association with rafts was increased by RANKL stimulation. The disruption of rafts blocked the TRAF 6 translocation by RANK ligand and impeded the interaction between RANK and TRAF6. Our observations demonstrate that proper RANK signaling requires the function of raft membrane microdomains.
\end{abstract}

Keywords: membrane microdomains; receptors; signal transduction; tumor necrosis; tumor necrosis factor

\section{Introduction}

Osteoclasts are multinucleated giant cells responsible for bone resorption. These cells are differentiated from hematopoietic myeloid precursors of the monocyte/ macrophage lineage (Suda et al., 1992). For the differentiation of osteoclast precursors into mature osteoclasts, a cell-to-cell interaction between osteoclast precursors and osteoblasts/stromal cells are required (Udagawa et al., 1990). Recently, many studies have provided ample evidences that the TNF family member RANKL (receptor activator of NF-KB ligand; also known as ODF, OPGL, and TRANCE) is expressed on the surface of osteoblasts/stromal cells and essential for osteoclast differentiation (Anderson et al., 1997; Yasuda et al., 1998; Takahashi et al., 1999). When its receptor RANK was stimulated by RANKL, several TNF receptor-associated factors (TRAFs), especially TRAF6, can be directly recruited into RANK cytoplasmic domains and may trigger downstream signaling molecules for the activation of NF- $\mathrm{KB}$ and mitogen activated protein kinases (MAPKs) (Darnay et al., 1998; Wong et al., 1998; Kim et al., 1999). The essential role of RANKL, RANK, and TRAF6 were clearly demonstrated in gene-deficient mice that displayed osteopetrotic phenotype due to defective osteoclastic bone resorption (Dougall et al., 1999; Kong et al., 1999; Lomaga et al., 1999; Naito et al., 1999). In addition to the study of TRAF6 ${ }^{-1-}$ mice, the biological significance of the TRAF6-Src signaling pathway in osteoclast differentiation and activation was showed that the association of TRAF6 with Src family kinases and subsequent stimulation of the Src kinase activity mediated phosphoinositide 3-kinase (PI3K)/Akt activation (Wong et al., 1999).

Lipid rafts are specialized membrane microdomains in the plasma membranes. They are enriched in glycosphingolipids and cholesterol, and incorporate specific proteins, among which are many glycosylphosphatidylinositol (GPI)-anchored proteins (Brown and London, 1998; Simons and Toomre, 2000) and $\mathrm{Src}$ family kinases. As lipid rafts resist solubilization in non-ionic detergent, following solubilization such non-solubilized membranes can be isolated from the soluble material based on their buoyant density, usually on sucrose gradient (Brown and London, 1998). Raft microdomains are most abundant at the plasma membrane, but may also be present in endocytic and secretory pathways. Membrane lipidation with saturated acyl chain groups of the raft-associated proteins, 
such as GPI-anchored proteins and double acylated proteins, have been found to participate in their preferential membrane lipid raft localization (Brown and London, 1998; Simons and Toomre, 2000). However, certain transmembrane proteins can also be enriched in rafts through a mechanism still unclear. The involvement of rafts has been implicated in many important cellular processes, which include generation and maintenance of cellular polarity, chemotactic migration, and cell surface receptor signaling. For $\mathrm{T}$ cell and $B$ cell antigen receptors, lipid rafts play a key role in receptor signaling, in which selective signaling molecules are recruited or segregated away (Cherukuri et al., 2001). Antigen or antibody-mediated cross-linking of the receptor facilitates its translocation into raft microdomains containing myristate- and palmitatemodified Src family kinases, which initiate signaling cascades by phosphorylating tyrosine residues on the nonenzymatic receptor complexes.

Recently, the association with lipid rafts of some members of the tumor necrosis factor receptor (TNFR) family, including CD40, has been reported (Vidalain et al., 2000). The tumor necrosis factor receptor-associated factor (TRAF) proteins are key signaling adaptor molecules utilized by many TNFR family receptors. Among the six mammalian TRAF family proteins, TRAF2 and TRAF3 were shown to be recruited to raft microdomains during CD40 signaling (Hostager et al., 2000; Vidalain et al., 2000). Similarly, the association of TRAF2 with caveolin-1, a component that along with rafts constitutes caveolae, has been reported (Feng et al., 2001). The association of CD40 and TRAF in raft microdomains raises the possibility that rafts may function as the signaling platform for the TNFR group of transmembrane proteins as in the case for the immune cell antigen receptors.

Based on that TRAF6 molecules are essential for osteoclast function and RANK signaling, we sought to address the potential role of membrane rafts for signaling by RANK and TRAF6. We found that the majority of the ectopically expressed RANK and substantial portion of endogenous TRAF6 were detected in the low-density raft fractions and TRAF6 was recruited to rafts by RANKL stimulation. And disruption of rafts impeded interaction between RANK and TRAF6.

\section{Materials and Methods}

\section{Reagents}

DMEM and FBS were purchased from Invitrogen Life Technologies. Anti-TRAF2 $(\mathrm{H}-249)$ and anti-TRAF6 $(\mathrm{H}-274)$ were purchased from Santa Cruz Biotechnology. Anti-flotillin was obtained from BD Biosciences and anti-T7 was from Novagen.

\section{Cell transfection}

293 cells, the human embryonic kidney cell line, were maintained in DMEM containing $10 \%$ FBS. For transient transfection, $2 \times 10^{5}$ cells were plated onto a well of 6 -well plates. The next day, transfection was carried out with SuperFect reagent (Qiagen) following the manufacturer's instruction. $40-48 \mathrm{~h}$ after transfection, cells were harvested. The mammalian expression plasmid encoding T7-tagged full-length human RANK was described previously (Kim et al., 1999).

\section{Isolation of rafts}

Rafts were isolated by a discontinuous sucrose density gradient ultracentrifugation. Cells were washed with ice-cold PBS and lysed in $2 \mathrm{ml}$ of ice-cold TNE buffer $(50 \mathrm{mM}$ Tris- $\mathrm{HCl}, \mathrm{pH} 7.4,150 \mathrm{mM} \mathrm{NaCl}$, and $1 \mathrm{mM}$ EDTA with protease and phosphatase inhibitors) containing $0.5 \%$ Brij 58 . The lysate was incubated on ice for $30 \mathrm{~min}$ and mixed with an equal volume of $80 \% \mathrm{wt} / \mathrm{vol}$ sucrose in TNE. The mixture was overlaid with $4 \mathrm{ml}$ of $35 \%$ sucrose, which in turn was topped with $4 \mathrm{ml}$ of $5 \%$ sucrose. The gradient was subjected to ultracentrifugation at $38,000 \mathrm{rpm}$ in an SW41 rotor (Beckman Instruments) for $18 \mathrm{~h}$ at $4^{\circ} \mathrm{C}$. After centrifugation, $1 \mathrm{ml}$ fractions were collected from the top of the gradient. Fractions were analyzed for the raft marker protein flotillin.

\section{Cell fractionation}

Cells were washed with ice-cold PBS and lysed in ice-cold TNE buffer containing $0.5 \%$ Brij 58 followed by incubation on ice for $30 \mathrm{~min}$. Insoluble fractions were pelleted by microcentrifugation at $14,000 \mathrm{rpm}$ for $20 \mathrm{~min}$. The supernatant was removed and considered soluble (S) fraction. The insoluble pellet was resuspended in the lysis buffer supplemented with 60 $\mathrm{mM} N$-octyl- $\beta$-D-glucopyranoside and $0.3 \%$ deoxycholic acid, incubated for $1 \mathrm{~h}$ on ice, and microcentrifuged for $20 \mathrm{~min}$ at $14,000 \mathrm{rpm}$. The supernatant from this step was referred to as insoluble (I) fraction. The whole process was performed below $4^{\circ} \mathrm{C}$.

\section{Western blotting analysis}

Total cell lysates were prepared by lysing cells in TNE $/ 0.5 \%$ Brij 58 buffer supplemented with $60 \mathrm{mM}$ $\mathrm{N}$-octyl- $\beta$-D-glucopyranoside and $0.3 \%$ deoxycholic acid for $1 \mathrm{~h}$ on ice and obtaining the supernatants by microcentrifugation at $14,000 \mathrm{rpm}$ for $20 \mathrm{~min}$. Total cell lysates or the fractionated cellular proteins described above were resolved by SDS-PAGE and transferred to a polyvinylidene difluoride membrane. The membrane was probed with a primary antibody followed by incubation with an appropriate secondary antibody conjugated to horseradish peroxidase. The immune 
complexes were detected with an enhanced chemiluminescence system.

\section{Imm unoprecipitation}

Association of RANK with TRAF6 is dependent on the integrity of lipid rafts. RANK-T7 transfected 293 cells were incubated for $4 \mathrm{~h}$ in serum-free media, pretreated with or without MCD $(15 \mathrm{mM})$ for $30 \mathrm{~min}$, then stimulated with RANKL $(500 \mathrm{ng} / \mathrm{ml})$ for $15 \mathrm{~min}$. Total cell lysates were immunoprecipitated with anti-T7 Ab, followed by immunoblotted with anti-T7, TRAF6, and TRAF2 antibodies.

\section{Results}

RANK and TRAF6 are localized in fractionationated rafts in RANK-overexpressing 293 cells

Despite the growing appreciation of the importance of lipid raft microdomains in transducing external stimulatory signals by membrane receptors, the involvement of and the role played by rafts in RANK signaling pathway have not been fully elucidated. We therefore investigated whether lipid rafts have any importance for the RANK signaling. To explore this possibility, we first examined the potential of RANK and TRAF6 for being associated with rafts in cells overexpressing RANK. The human embryonic kidney cell line 293 was transfected with a T7-tagged RANK expression plasmid. Raft fractions were separated by sucrose density gradient centrifugation. The majority of the ectopically expressed RANK (Figure 1, top panel) and substantial portion of endogenous TRAF6 (Figure 1, 2nd panel) were detected in the low-density raft fractions where the raft marker protein flotillin was exclusively present (Figure 1, bottom panel). A greater portion of endogenous TRAF2 was localized in raft fractions than in non-raft fractions (Figure 1, 3rd panel).

\section{RANK and TRAFG are localized in detergent-insoluble fractions in RANK-overexpressing 293 cells}

Lipid rafts were initially defined by their solubility in cold, non-ionic detergents. When RANK-T7-transfected 293 cells were treated with $0.5 \%$ Brij 58 (a mild nonionic detergent) below $4{ }^{\circ} \mathrm{C}$, the flotillin, marker protein for raft, was exclusively localized in the insoluble fraction (Figure 2, bottom panel). This means that the experimental conditions were valid for raft separation. Most of the ectopically expressed RANK was resistant to detergent solubilization in 293 cells (Figure 2, top panel, lanes 3 vs. 4). The endogenous TRAF6 and TRAF2 proteins were almost
Fraction 122344567889101112

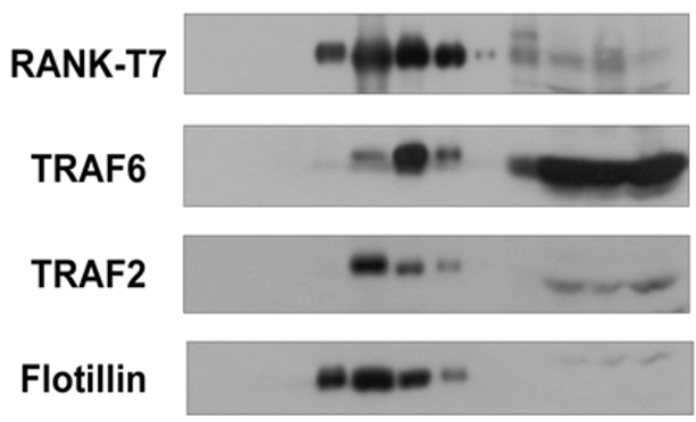

Figure 1. Localization of RANK and TRAF6 in fractionated rafts. 293 cells were transfected with RANK-T7 and cultured for $40 \mathrm{~h}$. RANK-T7 transfected 293 cells were lysed in a buffer containing 0.5\% Brij 58 and the lysates fractionated on sucrose density. Fractions were collected from the top of the gradients and the distribution of indicated proteins was assessed by Western blotting.

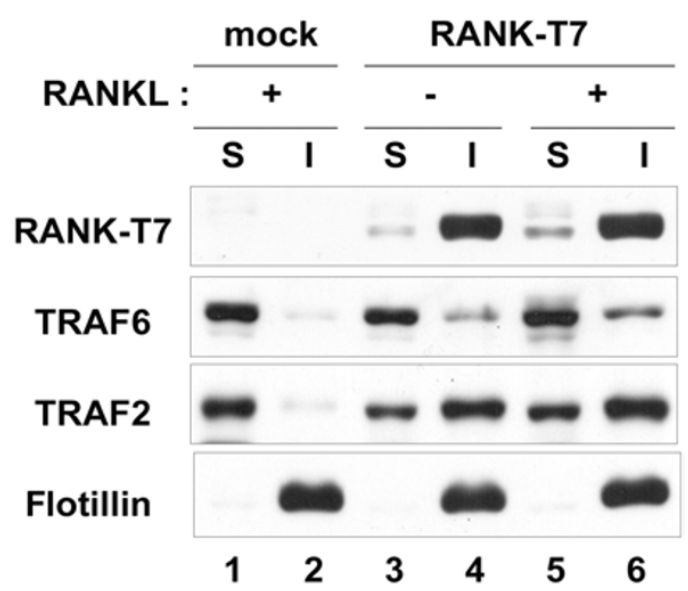

Figure 2. Localization of RANK and TRAF6 in detergent-insoluble fractions in RANK-overexpressing 293 cells. Mock or RANK-T7 transfected 293 cells were starved for $4 \mathrm{~h}$ in serum-free medium. Cells were stimulated with RANKL $(500 \mathrm{ng} / \mathrm{ml})$ for $15 \mathrm{~min}$ and lysed in a buffer containing $0.5 \%$ Brij $58.30 \mathrm{mg}$ of proteins from the Brij 58-soluble (S) and Brij 58-insoluble (I) fractions were analyzed by immunoblotting.

completely soluble in mock-transfected cells (Figure 2, 2nd and 3rd panels, lanes 1 and 2). The over-expression of RANK caused a translocation of significant portions of the TRAF proteins into the detergentinsoluble fraction (Figure 2, 2nd and 3rd panels, lanes 2 vs. 4). The translocation of TRAF6, and by a less extent that of TRAF2, was further increased upon stimulation with RANKL (Figure 2, 2nd and 3rd panels, lanes 4 vs. 6). As gene transfection in these cells often results in a constitutive activation of the gene product, thought to be caused by over-expressioninduced protein aggregation, it is possible that the 


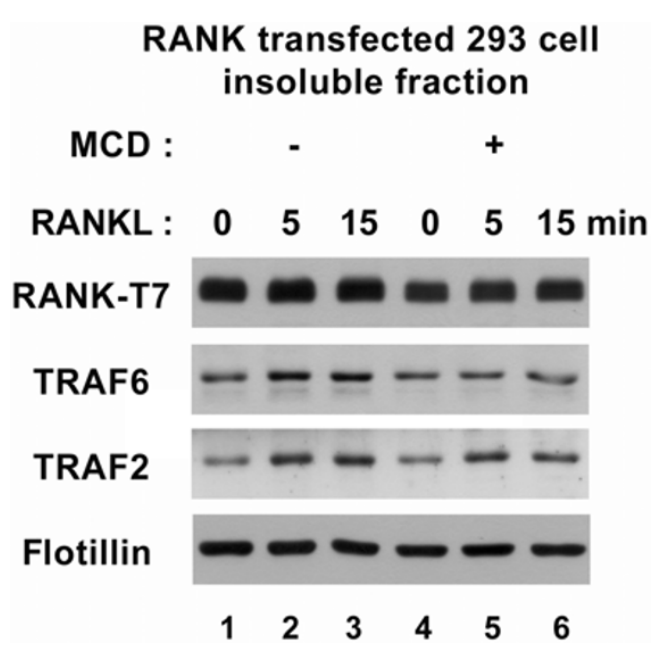

Figure 3. MCD treatments block TRAF6 translocation. RANK-T7 transfected 293 cells were incubated for $4 \mathrm{~h}$ in serum-free medium, pretreated with or without MCD $(15 \mathrm{mM})$ for $30 \mathrm{~min}$, then stimulated with RANKL $(1 \mu \mathrm{g} / \mathrm{ml})$ for the indicated time. Cells were lysed in a buffer containing $0.5 \%$ Brij 58 and the insoluble fractions were subjected to Western blotting with antibodies for the indicated proteins.

presence of TRAF6 and TRAF2 in the insoluble fraction in the unstimulated RANK-transfected cells (Figure 2, lane 4) was dependent on the basal activation of RANK. Therefore, these results suggest that activated RANK, localized in rafts, can recruit TRAF6 and TRAF2 to form a signaling complex.

\section{Raft-disrupting agents block TRAF6 translocation Induced by RANKL}

To evaluate the significance of TRAF6 translocation into rafts, which occurs in a manner dependent on RANK activation (Figure 2), we next assessed effects of methyl- $\beta$-cyclodextrin (MCD) on TRAF6 distribution and RANK signaling. MCD and filipin have been reported to extract and sequester, respectively, cholesterol and thereby disrupt raft microdomains (Kilsdonk et al., 1995; Vereb et al., 2000). MCD treatment of 293 cells transfected with RANK resulted in a slight decrease in detergent-insoluble fraction of RANK (Figure 3, top panel). More significantly, MCD blocked the RANKL-stimulated translocation of TRAF6 into the detergent-insoluble fraction in these cells (Figure 3 , 2nd panel). The translocation of TRAF2 was also affected by MCD, albeit by a less extent (Figure 3, 3rd panel).

\section{Raft disruption blocks the association of RANK with TRAF6 but not with TRAF2}

We next examined effects of raft disruption on RANK signaling. The interaction of RANK with TRAF adaptor molecules is the initial step in RANK signaling. The

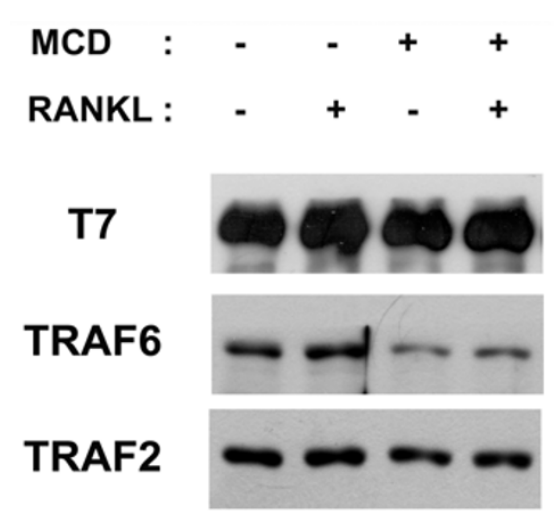

Figure 4. RANK interacts with TRAF6 in rafts. RANK-T7 transfected 293 cells were incubated for $4 \mathrm{~h}$ in serum-free medium, pretreated with or without MCD $(15 \mathrm{mM})$ for $30 \mathrm{~min}$, then stimulated with RANKL $(500 \mathrm{ng} / \mathrm{ml})$ for $15 \mathrm{~min}$. Total cell lysates were immunoprecipitated with anti-T7 Ab, followed by Western blotting with antibodies for the indicated proteins.

association of RANK with TRAF6 has been shown to result in the activation of $\mathrm{c}-\mathrm{Src}, \mathrm{Akt}$, and $\mathrm{PI} 3 \mathrm{~K}$ and be important for osteoclast function and survival. RANK, when over-expressed in 293 cells, coimmunoprecipitated with endogenous TRAF6 and TRAF2 (Figure 4). However, the RANK/TRAF6 interaction was significantly reduced by MCD pretreatment whereas the RANK/TRAF2 interaction was not affected (Figure 4). The reduced RANK/TRAF6 interaction may be due to the decreased TRAF6 translocation into raft microdomains by MCD treatment (Figure 3). This result indicates that raft integrity is necessary for RANK/TRAF6 association.

\section{Discussion}

Lipid rafts are specialized membrane microdomains which were initially defined by their insolubility in cold, non-ionic detergents and have been postulated to function as a signaling platforms for immune cell surface receptors such as TCT, BCR, and FceR (Sheets et al., 1999; Janes et al., 2000; Cheng et al., 2001). More recently, an integral role of the membrane lipid rafts in proximal signaling events has been demonstrated for the TNFR family member such as CD40. CD40 engagement leads to a membrane- associated recruitment of TRAF 3 to CD40's cytoplasmic domain (Vidalain et al., 2000). The TRAF family molecules are cytoplasmic adaptor proteins known to mediate signaling events specifically for members of the TNFR family (Darnay et al., 1998; Kim et al., 1999). To date six members of the TRAF family have been identified. Among these proteins, TRAF6 has been suggested to mediate the NF- $\mathrm{KB}$ activation by 
CD40, IL-1 receptor, RANK, two LPS receptors Tolllike receptor 2 (TLR2) and TLR4 (Bradley and Pober, 2001; Chung et al., 2002). The pivotal role of RANKTRAF6 signaling for the generation of functional osteoclasts has been evidenced by gene-targeting mouse studies in which TRAF6 deficiency led to osteopetrotic phenotype (Dougall et al., 1999; Lomaga et al., 1999; Naito et al., 1999). The defect in bone modeling is likely due to impaired TRAF6-mediated signal transduction for the RANKL/RANK interaction that initiates either osteoclast activation or osteoclast differentiation (Dougall et al., 1999; Lomaga et al., 1999; Naito et al., 1999). In our previous works, raft disruption with cholesterol sequestering agents selectively impaired the RANKL signaling pathways of Akt activated through TRAF6-Src pathway. Furthermore, raft-disrupting agents destroyed the integrity of actin-ring structure, boneresorbing activity, and survival of osteoclasts. However, raft disruption did not impaired MAPK and NF-KB activation by RANKL (Ha et al., 2003). In this study, we demonstrated that the majority of the overexpressed RANK was localized in lipid rafts portion (Figure 1). RANK over-expression provoked the translocation of TRAF6 into the detergent-insoluble raft fraction (Figure 2 and 3 ). Although a significant fraction of TRAF6 was present in raft microdomains, greater portion of TRAF6 was detected outside rafts (Figure 1). It may be possible that TRAF6 has differential roles within and outside lipid rafts. Our previous report that rafts disruption interfered the activation of Akt but not MAPK and NF- $\kappa B$ (Ha et al., 2003) support this possibility. It will be intriguing to investigate whether TRAF6 outside lipid rafts is fully functional for the activation of MAPK and NF-KB.

Raft disruption with a cholesterol-sequestering agent MCD reduced the association of RANK and TRAF6 (Figure 4), possibly due to reduced TRAF6 translocation into rafts, implicating that lipid rafts play a critical role in RANK-TRAF6 signaling. Src is one of the proteins of which expression greatly increases during osteoclast differentiation (Horne et al., 1992). RANKL stimulation of the catalytic activity of Src was reported and the recruitment of TRAF6 to form a tri-molecular complex with RANK and Src was suggested to result in the Src activation (Wong et al., 1999). Given that RANKL induces TRAF6 translocation into the detergent-insoluble fraction (Figures 2 and 3 ), it is possible that Src resident in rafts functions as a docking site for the RANK signaling complexes encompassing TRAF6. Rafts in osteoclasts may function as the platform for a network of signaling molecules that start to assemble in response to external stimuli such as RANKL. In the assembly process RANKL-induced recruitment of TRAF6 to RANK and to rafts may be an early event. The raftrecruitment may stimulate the interaction of Src, re- sident constitutively in rafts, with RANK-TRAF6 complexes, leading to the activation of Src.

\section{References}

Anderson DM, Maraskovsky E, Billingsley WL, Dougall WC, Tometsko ME, Roux ER, Teepe MC, DuBose RF, Cosman $D$, Galibert LA. Homologue of the TNF receptor and its ligand enhance T-cell growth and dendritic-cell function. Nature 1997;390:175-95

Bradley JR, Pober JS. Tumor necrosis factor receptor-associated factors (TRAFs). Oncogene 2001;20:6482-91

Brown DA., London E. Functions of lipid rafts in biological membranes. Annu Rev Cell Dev Biol 1998;14:111-36

Cheng PC, Cherukuri A, Dykstra M, Malapati S, Sproul T, Chen MR, Pierce SK. Floating the raft hypothesis: the roles of lipid rafts in B cell antigen receptor function. Semin Immunol 2001;13:107-14

Cherukuri A, Dykstra M, Pierce SK. Floating the raft hypothesis: lipid rafts play a role in immune cell activation. Immunity 2001;14:657-60

Chung JY, Park YC, Ye H, Wu H. All TRAFs are not created equal: common and distinct molecular mechanisms of TRAFmediated signal transduction. J Cell Sci 2002;115:679-88

Darnay BG, Haridas V, Ni J, Moore PA, Aggarwal BB. Characterization of the intracellular domain of receptor activator of NF-kappaB (RANK). Interaction with tumor necrosis factor receptor-associated factors and activation of NFkappab and C-Jun N-terminal kinase. J Biol Chem 1998;273: 20551-5

Dougall WC, Glaccum M, Charrier K, Rohrbach K, Brasel K, De Smedt T, Daro E, Smith J, Tometsko ME, Maliszewski CR, Armstrong A, Shen V, Bain S, Cosman D, Anderson $D$, Morrissey PJ, Peschon JJ, Schuh J. RANK is essential for osteoclast and lymph node development. Genes Dev 1999;13:2412-24

Feng X, Gaeta ML, Madge LA, Yang JH, Bradley JR, Pober JS. Caveolin-1 associates with TRAF2 to form a complex that is recruited to tumor necrosis factor receptors. J Bio Chem 2001;276:8341-9

$\mathrm{Ha} H$, Kwak HB, Lee SK, Na DS, Rudd CE, Lee ZH, Kim $\mathrm{HH}$. Membrane rafts play a crucial role in receptor activator of nuclear factor kappaB signaling and osteoclast function. $J$ Biol Chem 2003;278:18573-80

Horne WC, Neff L, Chatterjee D, Lomri A, Levy JB, Baron R. Osteoclasts express high levels of pp60c-src in association with intracellular membranes. J Cell Biol 2001;119: 1003-13

Hostager BS, Catlett IM, Bishop GA. Recruitment of CD40 and tumor necrosis factor receptor-associated factors 2 and 3 to membrane microdomains during CD40 signaling. J Biol Chem 2000;275:15392-8

Janes PW, Ley SC, Magee AI, Kabouridis PS. The role of lipid rafts in $T$ cell antigen receptor (TCR) signalling. Semin Immunol 2000;12:23-34 
Kilsdonk EP, Yancey PG, Stoudt GW, Bangerter FW, Johnson WJ, Phillips MC, Rothblat GH. Cellular cholesterol efflux mediated by cyclodextrins. J Biol Chem 1995;270: 17250-6

Kim HH, Lee DE, Shin JN, Lee YS, Jeon YM, Chung $\mathrm{CH}$, $\mathrm{Ni}$ J, Kwon BS, Lee ZH. Receptor activator of NF-kappaB recruits multiple TRAF family adaptors and activates c-Jun N-terminal kinase. FEBS Lett 1999;443:297-302

Kong YY, Yoshida H, Sarosi I, Tan HL, Timms E, Capparelli C, Morony S, Oliveira-dos-Santos AJ, Van G, Itie A, Khoo W, Wakeham A, Dunstan CR, Lacey DL, Mak TW, Boyle WJ, Penninger JM. OPGL is a key regulator of osteoclastogenesis, lymphocyte development and lymph-node organogenesis. Nature 1999;397:315-23

Lomaga MA, Yeh WC, Sarosi I, Duncan GS, Furlonger C, Ho A, Morony S, Capparelli C, Van G, Kaufman S, Heiden A van der, Itie A, Wakeham A, Khoo W, Sasaki T, Cao Z, Penninger JM, Paige CJ, Lacey DL, Dunstan CR, Boyle WJ, Goeddel DV, Mak TW. TRAF6 deficiency results in osteopetrosis and defective interleukin-1, CD40, and LPS signaling. Genes Dev 1999;13:1015-24

Naito A, Azuma S, Tanaka S, Miyazaki T, Takaki S, Takatsu K, Nakao K, Nakamura K, Katsuki M, Yamamoto T, Inoue J. Severe osteopetrosis, defective interleukin-1 signalling and lymph node organogenesis in TRAF6-deficient mice. Genes Cells 1999;4:353-62

Sheets ED, Holowka D, Baird B. Membrane organization in immunoglobulin E receptor signaling. Curr Opin Chem Biol 1999:3:95-9

Simons K, Toomre D. Lipid rafts and signal transduction. Nat Rev Mol Cell Biol 2000;1:31-9

Suda T, Takahashi N, Martin TJ. Modulation of osteoclast differentiation. Endocr Rev 1992;13:66-80
Takahashi N, Udagawa N, Suda T. A new member of tumor necrosis factor ligand family, ODF/OPGL/TRANCE/RANKL, regulates osteoclast differentiation and function. Biochem Biophys Res Commun 1999;256:449-55

Udagawa N, Takahashi N, Akatsu T, Tanaka H, Sasaki T, Nishihara T, Koga T, Martin TJ, Suda T. Origin of osteoclasts: mature monocytes and macrophages are capable of differentiating into osteoclasts under a suitable microenvironment prepared by bone marrow-derived stromal cells. Proc Natl Acad Sci USA 1990;87:7260-4

Vereb G, Matko J, Vamosi G, Ibrahim SM, Magyar E, Varga S, Szollosi J, Jenei A, Gaspar RJr, Waldmann TA, Damjanovich S. Cholesterol-dependent clustering of IL-2Ralpha and its colocalization with HLA and CD48 on T lymphoma cells suggest their functional association with lipid rafts. Proc Natl Acad Sci USA 2000;97:6013-8

Vidalain PO, Azocar O, Servet-Delprat C, Rabourdin-Combe C, Gerlier D, Manie S. CD40 signaling in human dendritic cells is initiated within membrane rafts. EMBO J 2000;19: 3304-13

Wong BR, Josien R, Lee SY, Vologodskaia M, Steinman RM, Choi Y. The TRAF family of signal transducers mediates NF-kappaB activation by the TRANCE receptor. J Biol Chem 1998;273:28355-9

Wong BR, Besser D, Kim N, Arron JR, Vologodskaia M, Hanafusa $\mathrm{H}$, Choi $\mathrm{Y}$. TRANCE, a TNF family member, activates Akt/PKB through a signaling complex involving TRAF6 and c-Src. Mol Cell 1999;4:1041-9

Yasuda H, Shima N, Nakagawa N, Yamaguchi K, Kinosaki M, Mochizuki SI, Tomoyasu A, Yano K, Goto M, Murakami A, Tsuda E, Morinaga T, Higashio K, Udagawa N, Takahashi $\mathrm{N}$, Suda T. Osteoclast differentiation factor is a ligand for osteoprotegerin/osteoclastogenesis-inhibitory factor and identical to TRANCE-RANKL. Proc Natl Acad Sci USA 1998;95: 3579-602 